Rhode Island College

Digital Commons @ RIC

\title{
Assessing Knowledge and Attitudes Toward Spirituality and Spiritual Care in APRN Students
}

\author{
Beth Susan Perry \\ Rhode Island College
}

Follow this and additional works at: https://digitalcommons.ric.edu/etd

Part of the Other Nursing Commons

\section{Recommended Citation}

Perry, Beth Susan, "Assessing Knowledge and Attitudes Toward Spirituality and Spiritual Care in APRN Students" (2016). Master's Theses, Dissertations, Graduate Research and Major Papers Overview. 151.

https://digitalcommons.ric.edu/etd/151

This Major Paper is brought to you for free and open access by the Master's Theses, Dissertations, Graduate Research and Major Papers at Digital Commons @ RIC. It has been accepted for inclusion in Master's Theses, Dissertations, Graduate Research and Major Papers Overview by an authorized administrator of Digital Commons @ RIC. For more information, please contact digitalcommons@ric.edu. 



\section{ASSESSING KNOWLEDGE AND ATTITUDES TOWARD SPIRITUALITY AND}

\section{SPIRITUAL CARE IN APRN STUDENTS}

A Major Paper Presented

by

Beth Susan Perry

\section{Approved:}

Committee Chairperson

Committee Members

(Date)

(Date)

(Date)

Director of Master's Program

(Date)

Dean, School of Nursing 


\title{
ASSESSING KNOWLEDGE AND ATTITUDES TOWARD SPIRITUALITY AND SPIRITUAL CARE IN APRN STUDENTS
}

\author{
by
}

Beth Susan Perry

A Major Paper Submitted in Partial Fulfillment

of the Requirements for the Degree of

Master of Science in Nursing

in

The School of Nursing

Rhode Island College

2016 


\begin{abstract}
Research has revealed patients' spiritual care needs are rarely addressed by both Registered Nurses and Advanced Practice Registered Nurses. The purpose of this project was to assess the attitudes and knowledge of APRN students toward spirituality and the provision of spiritual care. Graduate students $(\mathrm{N}=51)$ at a suburban institution in Rhode Island were surveyed using the Spirituality and Spiritual Care Rating Scale (SSCRS). The results revealed that although these participants had encountered patients with spiritual needs, 40 of the 51 surveyed $(78 \%)$ believed they had received inadequate training in the spiritual dimension of nursing care. Recommendations were made to improve the integration of content and training regarding spirituality and spiritual care into APRN programs.
\end{abstract}




\section{Acknowledgements}

There are many people I would like to thank for their support while I was writing this thesis. Bettyann, thank you for standing by me with love and encouragement everyday while I was pursuing my degree. I could not have accomplished obtaining my graduate degree without you. Thank you to my children and grandchildren, who were patient and understanding for those times I couldn't be with them during the course of the program when I was studying or writing. Dr. Sharon Galloway, who was my first reader and mentor, thank you for your incredible patience with me and your encouragement during this process. To my second reader and Director of the MSN program, Dr. Cindy Padula, thank you for your understanding and reassurance that I could achieve my goal. To my third reader, Dr Wendy Ossman, thank you for keeping me sane through this process and always encouraging me to keep walking through it. Finally, Dr. Debbie Servello, thank you for always being there for me no matter what. You are incredibly inspiring and truly a wonderful human being. 


\section{Table of Contents}

Background/Statement of the Problem...........................................

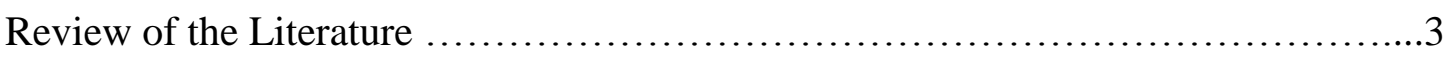

Theoretical Framework..................................................... 13

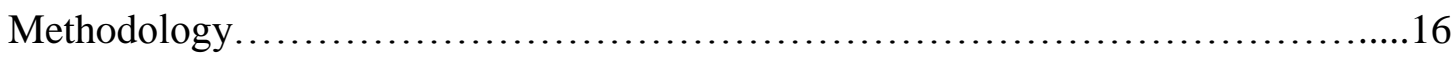

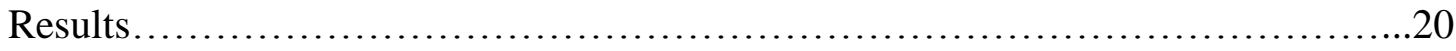

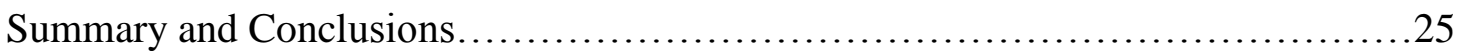

Recommendations and Implications for Advanced Nursing Practice................29

References.............................................................. 32

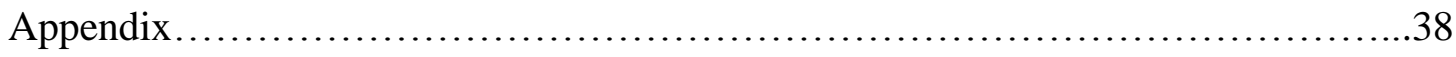


Assessing Knowledge and Attitudes toward Spirituality and Spiritual Care in APRN Students

\section{Background/Statement of the Problem}

In nursing, it is prudent that patients receive holistic care, or care of the mind, body and spirit. Accrediting bodies, such as the American Association of Colleges of Nursing (AACN), the National Organization of Nurse Practitioner Faculties (NONPF) and The Joint Commission (JC), as well as other organizations, have included in their standards the recommendation that spiritual care of the patient should be addressed (AACN, 2009; JC, 2009; NONPF, 2012). The North American Nursing Diagnosis Association (NANDA) has also recognized spiritual distress as a significant domain that needs to be addressed as part of patient care in an attempt to reduce suffering and promote wellbeing (NANDA, 2007). However, research has revealed patients' spiritual care needs are rarely addressed by both Registered Nurses and Advanced Practice Registered Nurses (APRNs) (Chrash, Mulich, \& Patton, 2011; Lewinson, McSherry \& Kevern, 2015). A recent systematic literature review by leading experts (Lewinson et al., 2015) described how nurses feel inadequately prepared to provide spiritual care and desire to be better informed and skilled in this domain. These authors suggested that the most prevalent reason for lack of spiritual care in practice relates to a perceived deficiency in academic preparation at both the undergraduate and graduate level in spiritual caregiving (Lewinson et al., 2015). This sentiment has been consistent in the literature for over two decades (Carr, 2013).

Chrash et al. (2011) discussed the integration of spiritual assessment into advanced care planning by APRNs, and discovered that one cannot presume that every APRN "has adequate holistic assessment skills and competencies or is able to integrate 
spiritual assessment into spiritual care" (p. 553). Evidence suggests that undergraduate programs may not adequately prepare nurses in the domain of spiritual care; therefore, they may enter into APRN programs with little practical experience and a weak knowledge base (Stranahan, 2001). If spiritual assessment and care are an important element of holistic treatment of the patient, it is imperative that APRNs feel confident and comfortable in providing this type of care (Chrash et al., 2011; Hubbell et al., 2006; Maddox, 2001; Weiland, 2010). Assessing current knowledge and attitudes among APRN students on spiritual caregiving is one way to evaluate the degree of preparation occurring within the academic setting and perhaps the need for further education within graduate curriculum. The purpose of this project was to assess the attitudes and knowledge of spirituality and spiritual caregiving of APRN students in order to make recommendations regarding educational preparation in graduate programs related to spiritual care.

Next, a review of the literature will be presented. 


\section{Review of the Literature}

The following databases were utilized for this project: CINAHL; SAGE;

PubMed; Medline and Science Direct. The keywords used were spirituality, spiritual care, nurse, nurse practitioner, student nurses, undergraduate, graduate, education and curriculum. The data was retrieved from January 1, 2001 to February 1, 2016.

\section{Spirituality: The Concept}

Although there is a plethora of nursing literature on the subject of spirituality, the profession itself has not reached a consensus on a specific definition of spirituality. It would be nearly impossible to cite all the attempts that have been made to do so over the last three decades (Weiland, 2010). Whether a person considers themselves spiritual and/or religious, they usually possess some type of perspective on matters concerning suffering, mortality, and the meaning of life itself (Taylor, Park, \& Pfeiffer, 2014). Spirituality and religion are words that are frequently used interchangeably. While spirituality is often associated with finding meaning and purpose in life, religion is equated with rites and rituals pertaining to a particular faith (Burkhart \& Hogan, 2008). Numerous aspects of the concept of spirituality are intangible and decidedly individual; however, there are common threads that allow us to approach the subject as a whole, such as the belief in some form of a power greater than oneself (Burkhart, Schmidt \& Hogan, 2011).

The sheer differences of perceptions of spirituality by various groups must not be overlooked. The definition of spirituality should therefore reflect a broad diversity of opinion and to that end a universal approach may be required to ensure inclusion of people of all spiritual/religious affiliations (McSherry, Cash \& Ross, 2004). 
Tanyi (2002) proposed such a definition:

Spirituality is a personal search for meaning and purpose in life...it entails connection to self-chosen and/or religious beliefs and values, motivating individuals to achieve their optimal being. This connection brings faith, hope, peace and empowerment. The results are joy, forgiveness of oneself and others, awareness and acceptance of hardship and mortality, a heightened sense of physical and emotional well-being and the ability to transcend beyond the infirmities of existence (p. 506).

O'Brien (2003), a known expert on spirituality in nursing, proposed spirituality is a personal concept, generally associated with an individual's attitudes and beliefs related to transcendence (God) or nonmaterial forces of life and nature. This author also recognized features such as love, compassion, caring and connection of body, mind and spirit as being used frequently in the nursing literature to define spirituality. Additional ideas discussed in the literature describe spirituality as it relates to one's values and connectedness to a higher power, others and the world (Sessanna, Finnell, Underhill, Chang, \& Peng, 2011).

Spiritual care in nursing has a long history and has been recognized as integral to nursing for centuries, beginning with the early Catholic religious orders and Florence Nightingale (Calabria \& Macrae, 1994; O’Brien, 2003) and continuing into the present day. Many different aspects of spiritual care have been studied over the last three decades. Nursing research has examined the meaning of spirituality itself, the implications of spirituality for nursing practice and the relationship between nurses own spiritual perceptions and the provision of spiritual care (Lewinson, McSherry \& Kevern, 
2015). Researchers have also studied how nurses attend to spiritual care in regards to terminal illness and spiritual distress (Taylor \& Mamier, 2013). In some instances, patients themselves have been the subject of studies concerning their own perception of spiritual care and how well it was provided by nurses (McSherry \& Ross, 2002). Many nursing theories have been designed concerning the approach to patients' spiritual dimension and well-being, including but not limited to Watson's Theory of Caring (2001), Burkhart and Hogan's Spiritual Care in Nursing Practice theory (2008) and Nardi and Rooda's Spirituality-Based Nursing Practice Theory (2011). One goal of this study was to suggest how education in the area of spirituality and spiritual caregiving could enhance spiritual care assessment and skills, resulting in improved outcomes relative to patients' spiritual needs.

\section{Spirituality Assessment Measures}

In relation to specifically educating nurses on spiritual care, assessment tools have been created to assist in evaluating patients' spiritual health (Burkhart, Schmidt \& Hogan, 2011). Two instruments noted in the literature include the HOPE and FICA. These tools are designed as mnemonics that can facilitate the holistic spiritual assessment of a patient. The HOPE questions serve as a teaching tool for healthcare providers in performing a spiritual assessment. These questions have not been validated by research, however, the authors believe there is value to their approach of using open-ended questions that allows for patient exploration (Anandarajah \& Hight, 2001). The $\mathbf{H}$ addresses patients' sources of hope, meaning, comfort, strength, peace, love and connection to others. The $\mathbf{O}$ inquires as to whether the patient is part of an organized religion, and the importance of religion in their life. The $\mathbf{P}$ questions whether or not the 
patient has any personal spiritual beliefs that are important to them. Finally, the $\mathbf{E}$ asks if the patient is experiencing any conflict between their beliefs and their medical care, including possible end-of-life care.

The FICA spiritual history tool (Puchalski, 1996) was developed as a guide for healthcare providers to incorporate spirituality into a standard comprehensive assessment. In a study by Borneman et al. (2010), data confirmed that the FICA was effective for assessing several dimensions of spirituality. The $\mathbf{F}$ inquires whether the patient has a faith or religion. The I investigates what importance and influence their faith has in their life. The $\mathbf{C}$ asks if the patient is part of a religious community, and if that community is a source of support to them in their illness. Lastly, the A questions how the patient would like the nurse to address spiritual issues in regards to their health care, for instance whether the patient would like to speak to a chaplain/clergy member to discuss spiritual matters.

\section{Nursing Education and Spiritual Care}

Research reviewed for this study also included ways to integrate spiritual care training into nursing curricula. Narayanasamy (1999) introduced the ASSET model, which stands for "auctioning spirituality and spiritual care in education and training" (p. 275). This model could be offered as a "stand alone module, or as a curriculum theme in a course" (Narayanasamy, 1999, p. 276). Narayanasamy’s model included experiential learning on the broad aspects of spirituality, as well as learning assessment, planning, implementation and evaluation skills of spiritual patient care (1999). Although this model has been used primarily for undergraduate education, it is appropriate for the graduate level as well. 
Subsequent teaching methods over the years have included mandatory readings in textbooks on spirituality, although a study by Timmins et al. (2015) reviewed 548 nursing texts and concluded current texts need to "provide a stronger leadership role in this area" (p. 6). Additional methods include required reflections on specific clinical patient interactions, student discussions regarding spiritual issues, role playing and simulation scenarios using standardized patients (Galloway, 2015; Giske, 2012).

Despite the progress made over the years with regard to spiritual care and assessment of patients, current literature demonstrates the need for a more definitive approach to teaching spiritual care in both graduate and undergraduate programs (Lewinson et al., 2015). As previously mentioned, it is well documented within the literature that academic and hospital accrediting bodies, as well as many nursing organizations, have identified the provision of spiritual care as a basic nursing competency. In 2008, the AACN published the Essentials of Baccalaureate Education. Essential IX, Standard 1 states "the baccalaureate program prepares the graduate to: 1 . Conduct comprehensive and focused physical, behavioral, psychological, spiritual, socioeconomic, and environmental assessments..." (AACN, 2008, p. 31). Despite this documentation, relevant literature demonstrates that spiritual care is not being provided with any consistency by practicing nurses (Lewinson et al., 2015).

Several reasons have been mentioned in the literature that attempt to explain the deficiency of spiritual caregiving in practice. Lack of time and administrative support are two examples. However, the most debated reason for not providing spiritual care pertains to lack of educational preparation. Lewinson et al. (2015) echo the underrepresentation of spiritual care content in nursing education and practice. The 
results of their international review generated four themes: 1. Spiritual Awareness; 2. Spiritual Assessment; 3. Spiritual Competence; and 4. Spirituality Content in PreRegistration Educational Programs. The authors concluded that the literature currently available recognizes and affirms the spiritual dimension in nursing as an established concept and that "nurses are aware of their role". However, "they require adequate education to fulfil this fundamental part of their role in order to deliver truly holistic care" (Lewinson et al., 2015, p.813). The study addressed the fact that institutions of higher learning were aware of the need to include the subject of spirituality within their nursing curricula. Nonetheless, spirituality and spiritual care in nursing education curriculum are not being integrated in a meaningful and deliberate way. The authors believed more research is needed in the area of spirituality and nurse education in order to promote its consistent inclusion into nursing education programs (Lewinson et. al, 2015).

\section{Spiritual Care and the APRN}

In the last two decades, there was a dearth of information regarding the provision of spiritual care by the APRN. Education for spiritual care is supported by the NONPF Nurse Practitioner Core Competencies (2012). Independent practice competency 4c states that the nurse practitioner "will incorporate the patient's cultural and spiritual preferences, values and beliefs into health care" (p.5). The Adult-Gerontology Acute Care Nurse Practitioners Competencies (2012) also address, in the competency focused on health promotion (Competency I), the need for the APRN "to distinguish cultural, spiritual, ethnic, gender and cohort differences in presentation, progression and treatment response of common acute, critical and chronic health problems" (p.14). 
The available literature relating to APRN practice and spiritual care began to emerge in the year 2000, suggesting a perceived lack of education by APRNs regarding the provision of spiritual care. Stranahan (2001) conducted a nonexperimental crosssectional survey to investigate the relationships between spiritual perception and attitudes about spirituality and the spiritual care practices of APRNs in Indiana $(N=102)$. In regard to spiritual care practice, more than half $(57 \%)$ of those surveyed reported they "rarely or never provided spiritual care" (p. 100). This number correlated with the percentage of respondents who felt they were inadequately prepared to provide such care in both their undergraduate and graduate programs. Stranahan recommended that although spiritual care was sometimes addressed in graduate nursing education curricula, it "may not be enough to achieve the desired outcome for students" (p. 102). The author suggested that specific courses in spiritual care may be necessary to aid APRN students in identifying the spiritual needs of patients in order to develop appropriate interventions.

Maddox (2001) conducted a study in which she reviewed spiritual assessment tools and evaluated their capacity to enhance spiritual assessment within the curriculum of a clinical course for APRNs. The purpose of the course was to assist NP students in addressing their clients' spiritual wellbeing. Maddox believed that "as educators continue to redefine exactly what is needed in various NP curriculum models, content on spirituality and spiritual assessment should always be included" (p.139). The study concluded that a majority of her NP students in this class $(N=18)$ felt their ability to assess their patients' spiritual wellbeing had improved following participation in the course. Maddox also recommended that all APRNs should become comfortable 
providing some type of spiritual care in order to fulfill their professional responsibility to their patients.

Following the study by Maddox, there was a five-year gap in the literature related to APRNs and spiritual assessment and caregiving. Hubbell et al. (2006) explored a sample of APRNs $(N=101)$, who were chosen through systematic sampling, to discover if and how spiritual care was integrated into their practice. A survey entitled the Nurse Practitioner Spiritual Care Perspective Survey (NPSCPS) was mailed to practicing APRNs and out of 101 mailings, there was a $65 \%$ return rate. Eighteen of the participants $(28 \%)$ stated that they had received no formal education for providing spiritual care and half of the participants felt the education received in spiritual care was "inadequate in relation to what they needed in practice" (p. 383). Seventy-three percent of participants did not customarily provide spiritual care to their patients due to their perceived educational barriers.

Tanyi et al. (2009) conducted a qualitative study among a small group of primary care practitioners that included doctors, APRNs and physician assistants (PAs). The authors found that education, or lack thereof, was among a number of barriers faced regarding spiritual caregiving. It was recommended that in order to manage the barrier of lack of education, practitioners could attend seminars, employ evidence based practice through journal review and share information with colleagues to gain insight into spiritual care. This continuing and shared education was found to be essential in supporting patients' spirituality.

Weiland (2010) conducted a study that applied Roy's adaptation model to clinical practice in an attempt to reinforce an APRNs responsibility to incorporate spiritual care 
in a critical care environment. The author postulated that Roy's model viewed the patient as a holistic system that adapts to health and illness and that humans are spiritual beings; therefore "spirituality is relational" (p. 285). Her concern was that in the critical care environment in which she worked, spiritual care was being overlooked. Weiland noted that APRN participants in studies she reviewed reported feeling uncomfortable providing spiritual care to patients, professing a lack of knowledge and confidence in relation to assessing a patients' spiritual needs. Weiland discovered in her own professional work how important spiritual needs were to some of her patients well-being. She summarized her study by stating her belief that all nurses have a responsibility to integrate spiritual care into their practice because healing is central to the art of nursing and has been shown to "positively influence health and wellness" (Weiland, p. 289).

Carron and Cumbie (2011) conducted a small study of descriptive qualitative design based on grounded theory that used a phenomenological approach. Four groups of individuals participated in the study: adult primary care patients, family NPs, community spiritual leaders, educators and Benedictine nuns (Carron \& Cumbie, 2011). Themes that emerged reflected how spirituality is an unfamiliar topic of discussion. One NP stated "Spirituality is an uncomfortable thing to bring up. I think if I was trained more or had a tool I would be more comfortable bringing it up" (p. 556). Another common theme among NPs suggested that spiritual care evolved once they established a caring relationship with the patient. Many patients responding to a question on spiritual intervention believed that spiritual interventions could be interwoven into the flow of conversation with them or may simply include taking a walk or listening to music. The 
authors concluded that spiritual care can be implemented through both a caring nursepatient relationship and the use of evidence based assessment and interventions.

The literature pertaining to APRN education has also demonstrated that spiritual caregiving content is both required and necessary at the graduate level of nursing education, yet the inclusion of this important content has been neglected. It is essential in order for the APRN to feel comfortable providing competent and holistic spiritual care to their patients (AACN, 2012; Carron \& Cumbie, 2011; Hubbell et al., 2006; Maddox, 2001; NONPF 2012; Stranahan, 2001; Tanyi, et al., 2009; Weiland, 2010).

More research is needed to determine the best course of action to incorporate training in spiritual care into graduate nursing curricula. It is important to support this ongoing research with data demonstrating the need for improved practice among APRN students.

Next, the theoretical framework guiding the study design will be presented. 


\section{Theoretical Framework}

Nardi and Rooda's Spiritually-Based Nursing Practice Theory (2011) offers a framework and focus for applying research to spirituality-based nursing care. The conceptual model of this theory was adapted from the Rooda Conceptual Model of Multicultural Nursing (Rooda, 1992). These authors suggested this framework can be used to "determine the best curriculum, clinical experiences, and strategies to enhance students' ability to provide effective spirituality-based nursing care" (Nardi \& Rooda, 2011, p.263).

This theory was created based on inductive theory building and was intended to be a middle-range nursing theory. Nardi and Rooda (2011) developed this evidencebased theory to attempt to explain the ontological aspect of nursing care. The conceptual model in Figure 1 on the next page illustrates this evidence-based practice theory of spirituality-based nursing practice. The theory proposes nurses carry forth their personal spiritual awareness, while patients bring their unique spiritual need, to the nurse-patient relationship. Each of these individuals have different spiritual backgrounds, beliefs, behaviors and practices. In order for the nurse to meet the spiritual care needs of their patients, they must be able to recognize potential differences in the patient's beliefs from their own and exhibit an understanding of the patient's spiritual needs. The patient, in turn, brings their own expressions and behaviors relating to his or her beliefs as well as their spiritual care needs to the nurse. Based on the nurse's recognition and understanding of those needs, the nurse can then use a variety of spiritual interventions such as presence, prayer and support to comfort the patient. These actions by the nurse thus promote well-being and healing for the patient. Hence, "outcomes 


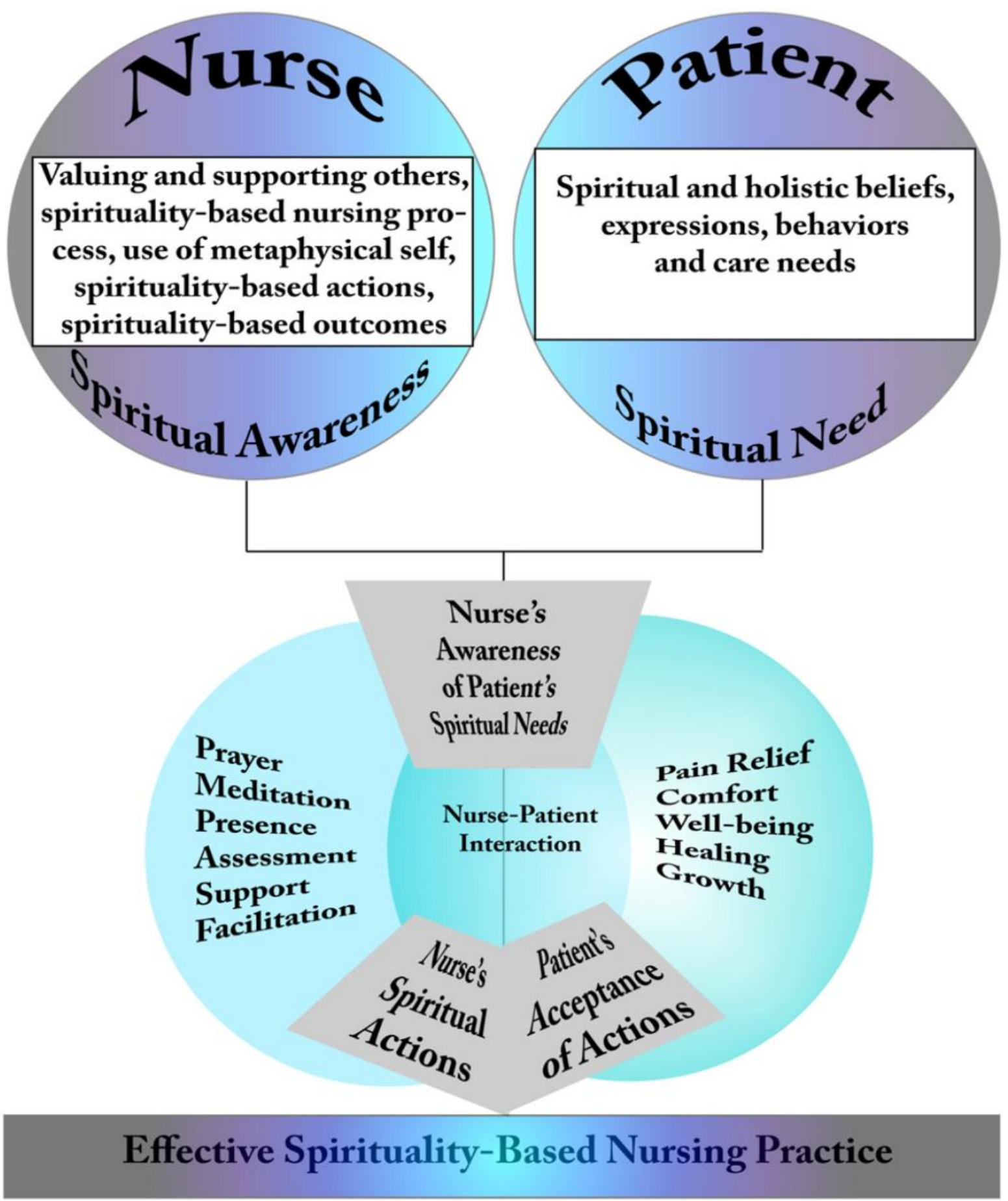

Figure 1. Practice Theory of Spiritual-Based Nursing Process

(Nardi \& Rooda, 2011) 
are in turn influenced by the patient's acceptance of and openness to the nurses use of these metaphysical interventions" (Nardi \& Rooda, p. 262). These actions in combination may enhance the patient's spiritual health and well-being.

Next, methodology used for this project will be discussed. 


\section{Methodology}

\section{Purpose}

The purpose of this project was to assess the attitudes and knowledge of spirituality and spiritual care of APRN students in order to make recommendations regarding educational preparation in graduate programs related to spiritual care.

\section{Design}

A quantitative design was used for this research, using Wilfred McSherry’s Spirituality and Spiritual Care Rating Scale (SSCRS) tool, a one time, 17 item self-report survey.

\section{Sample}

A convenience sample was recruited from students enrolled in the Masters of Nursing program at Rhode Island College. All programs within the Master's program were invited to participate on a volunteer basis, including Clinical Nurse Specialists, Acute Care Nurse Practitioners, Certified Registered Nurse Anesthetists and Public Health students. There were no exclusion criteria for this project.

Site

The project took place at Rhode Island College (RIC). The College is a coeducational public institution that was founded in 1854 . The campus covered roughly 180 acres located in a suburban setting. The total undergraduate and graduate enrollment was approximately 8,700 . The RIC student body was roughly $33 \%$ male and $67 \%$ female. The Nursing department offers BSN, RN-BSN, Master's and DNP programs of study. 


\section{Procedure}

This project was approved by the RIC IRB. Permission to use Wilfred McSherry's SSCRS survey tool was obtained via email. Permission to administer the survey following usual class time was requested via e-mail from all Professors in the graduate nursing program at RIC who were teaching courses during summer sessions I and II. Permission was granted by the professors and dates to address the individual classes were discussed. Data collection then took place in 2016 during summer sessions I and II.

An informational letter describing the purpose and voluntary nature of the study was provided by this author to all students who participated in the survey. The students were given the opportunity to read the letter and ask questions prior to their participation. The participants were assured the surveys would remain anonymous and that their confidentiality would be maintained. The informational letter also informed participants that their consent would be implied by completing the survey. The author left the room while the participants completed the survey and two manila envelopes were left in the classroom for them to deposit their completed surveys in. The completed surveys were kept by the author for the purpose of data collection and then locked in a secured cabinet in the graduate nursing office. Data was only accessible to the primary investigator and this author.

\section{Measurement}

A copy of the survey tool used for measurement of data can be found in Appendix A. The SSCRS is a 17- item self-report instrument that quantifies participants' perceptions of the extent to which they hold certain spiritual views and engage in 
spirituality related activities (McSherry, 2006). The SSCRS was constructed to address broad attributes of spirituality and spiritual care. The four subscales include (a) spirituality (existential elements of life and its meaning), (b) spiritual care (listening, spending time, privacy, respect), (c) religiosity (systems of faith and worship) and (d) personalized care (unique values, morals and relationships). The development of this scale used factor analysis to establish underlying associations in the SSCRS which may aid in understanding of spirituality and spiritual care as perceived by nurses (McSherry, Draper \& Kendrick, 2002). The SSCRS was created in an attempt to "aid in the investigation and measurement of Spirituality and Spiritual Care" and it was found that the scale "demonstrated a reasonable level of internal consistency reliability, having a Cronbach's alpha coefficient of 0.64" (McSherry et al., 2002 p.731). Cronbach's alpha is a reliability index that is used to estimate internal consistency of a complex measure composed of several subparts (Polit \& Beck, 2012). McSherry’s SSCRS also demonstrated reliability and validity and has been used in over forty-two studies in eleven different countries (McSherry \& Jamieson, 2011).

In parts A and B of this tool, demographic data is collected and includes the gender and age of the participant, qualifications, hours worked, number of years in nursing and specialty area. Part $\mathrm{C}$ is the actual survey consisting of 17 Likert scale questions which are followed by seven questions concerning the provision of spiritual care and education received regarding spiritual care. Part D consists of two questions regarding religion. Part E asks the participant a question pertaining to them only if they had decided not to fill out the survey. 


\section{Data Analysis}

A Microsoft Excel data analysis program was used. Data were entered and verified by the author. The mean and standard deviation related to each SSCRS question answered in Section $\mathrm{C}$ were analyzed using formulas in the Excel program to calculate the values individually; the data were then recorded. Demographic data were analyzed in the same manner, using formulas in the Excel program.

Data were analyzed by sections: Sections A, B, and D using descriptive statistics alone and section $\mathrm{C}$ (scale) using mean and standard deviation and descriptive statistics on two questions.

In the next section, the results will be discussed. 


\section{Results}

The SSCRS is broken into four sections, A, B, C, and D. Parts A, B, and D describe demographic data as well as religious affiliation, and part $\mathrm{C}$ is the actual survey, which contains four subscales.

Sections A and B of the survey were demographic in nature. Portions of descriptive statistics from these sections are displayed in Table $1(N=51)$.

\section{Table 1}

Demographics of Survey Participants ( $N=51)$

\begin{tabular}{|c|c|c|}
\hline \multicolumn{2}{|c|}{ Variable } & $\#(\%)^{*}$ \\
\hline & Male & $14(27.45)$ \\
\hline & Female & $37(72.54)$ \\
\hline \multicolumn{3}{|c|}{ Age (years) } \\
\hline & $21-29$ & $14(27.45)$ \\
\hline & $30-39$ & $20(39.21)$ \\
\hline & $40-49$ & $13(25.49)$ \\
\hline & $50-59$ & $4(7.84)$ \\
\hline & $60+$ & 0 \\
\hline
\end{tabular}

Length of Nursing Career (years)

$\begin{array}{rc}<1 & 1(1.96) \\ 1-5 & 19(37.25) \\ 6-10 & 17(33.33) \\ 11-25 & 9(17.65) \\ 25+ & 4(7.84)\end{array}$

${ }^{*}$ Percentages may not total $100 \%$ due to rounding and/or missing values.

Study participants $(N=51)$ included 37 females and 14 males, and ranged in age from approximately 18-60 years old. Approximately 64\% ( $n=33)$ participants worked full time and $31.37 \%(n=16)$ part time. The range of specialties include the Emergency 
Room (ER), Intensive Care (ICU) and Critical Care Unit (CCU). Most participants had been practicing nursing for 1-10 years.

The survey questions in section C, based on Likert-scale responses, were divided into four subscales: (a) Spirituality (Existential Elements), (b) Spiritual Care, (c) Religiosity and (d) Personalized Care. The results are displayed in Table 2.

Key findings from the questions presented in Table 2 are as followed: (a) Spirituality (Existential Elements): $\mathrm{M}=4.02, \mathrm{SD}=0.73$. Four variables dealt with issues concerning life with meaning and purpose and the need to find meaning and purpose during times of illness or hospitalization. Responses demonstrated that participants tend to agree that spirituality incorporates existential elements. (b) Spiritual Care: $M=4.39$, $\mathrm{SD}=0.68$. Five variables dealt with issues of spiritual care. Participants agreed that nurses must listen, spend time, respect privacy and dignity, maintain religious practices and deliver care by displaying qualities such as kindness and concern. (c) Religiosity: $\mathrm{M}=2.59, \mathrm{SD}=1.10$. Two variables dealt with issues regarding the idea that spirituality was not only a concept associated with religion, systems of faith, and worship but also a universal concept, unique to all people. It would appear that participants were seemingly opposed to the notion that spirituality only applies to religious people $(\mathrm{SD}=1.10)$. The final subscale was (d) Personalized Care: $\mathrm{M}=3.84, \mathrm{SD}=0.85$. Six variables measured underlying associations related to the dimension of spirituality, which is dictated by the need to accommodate personalized care, for example, values, morals, individual beliefs, and relationships. Responses validated that respondents agreed that it is important to address and respect patients' individuality it matters concerning morality and beliefs. 
Survey Responses SSCRS $S^{l}$ Subscales

\section{Spirituality}

Question

$\underline{\text { Mean }(\mathrm{SD})^{2}}$

f) I believe spirituality is about finding meaning in the good and bad events in life.

$3.76(0.76)$

h) I believe nurses can provide spiritual care by enabling a patient to find meaning and purpose in their illness.

$3.98(0.71)$

i) I believe spirituality is about having a sense of hope in life.

1) I believe spirituality is a unifying force which enables one to be at peace with oneself and the world.

\section{Spiritual Care}

a) I believe nurses can provide spiritual care by arranging a visit by the hospital Chaplain or the patient's own religious leader.

b) I believe nurses can provide spiritual care by showing kindness, concern and cheerfulness when giving care.

g) I believe nurses can provide spiritual care by spending time with a patient giving support and reassurance especially in time of need.

k) I believe nurses can provide spiritual care by listening to and allowing patients' time to discuss and explore their fears, anxieties and troubles.

n) I believe nurses can provide spiritual care by having respect

for privacy, dignity and religious and cultural beliefs of a patient.

Religiosity

d) I believe spirituality involves only going to Church/Place of Worship.

e) I believe spirituality is not concerned with a belief and faith in a God or Supreme Being.

Personalized Care

c) I believe spirituality is concerned with a need to forgive and be forgiven.

j) I believe spirituality is to do with the way one conducts one's life here and now

m) I believe spirituality does not include areas such as art, creativity, and self-expression.

o) I believe spirituality involves personal friendships, relationships.

p) I believe spirituality does not apply to Atheists or Agnostics.

$3.69(0.95)$

q) I believe spirituality includes people's morals.

$4.20(0.80)$

Portions of section C of the SSCRS asked additional questions regarding spiritual care. Participants were asked who they believed was responsible for providing spiritual 
care to patients. The majority $74.5 \%(n=38)$ responded that a combination of nurses, Chaplains/Clergy, patients themselves, patients' family and friends, and the patients' own religious leader were all responsible for the providing spiritual care.

Participants were also asked if they had ever encountered a patient with a spiritual need, how they became aware of that need and if they felt they could meet their patients' spiritual needs. The responses indicated that $92.16 \%(n=47)$ of nurses had encountered a patient with a spiritual need and that $66.66 \%(n=34)$ felt able to provide spiritual care and $23.52 \%(n=12)$ felt unable to provide this type of care. When given the opportunity to state why they felt unable to provide spiritual care, eight of the 12 participants noted it was due to time constraints. One participant stated they were uncomfortable because they identified as agnostic, and another participant felt spirituality should be addressed in an interdisciplinary fashion. The manner in which they became aware of their patients' needs varied and included reading information provided in a nursing care plan, observation of the patient/family and receiving cues from patients themselves.

The remainder of Section $\mathrm{C}$ of the survey pertained to where participants had received their undergraduate degree and whether or not they had ever received education by way of lecture in spirituality and spiritual care in their respective programs. The majority of participants had attended their BSN programs in the Northeast, however there were participants from other areas of the United States, as well as a few International students. In regards to receiving education concerning spiritual care in their programs, 26 $(50.98 \%)$ responded they had received spiritual care lecture content, while $23(45.09 \%)$ had not. The survey inquired whether the participants felt adequately prepared to provide spiritual care by their programs, as well as who they felt was responsible to provide 
spiritual care education. In relation to the question of whether participants felt they received sufficient training, $19.60 \%(n=10)$ felt they had and $78.43 \%(n=40)$ felt they had not. Overall, a majority of the participants felt education regarding spiritual care was the responsibility of Colleges and Universities, hospital in-services, and continuing education; the latter of which nurses could achieve on their own. Finally, participants were asked if they had completed any post baccalaureate continuing education in spiritual care. In this case, $11.76 \%(n=6)$ of participants had engaged in continuing education relating to spiritual care of the patient, while $86.27 \%(n=44)$ had not.

Section D contained two demographic questions inquiring whether the participants had a religious affiliation, and if they actively were practicing their religion. Findings revealed that $80.39 \%(n=41)$ were affiliated with a religious group, and $17.64 \%$ $(n=9)$ were not. Results also displayed $60.78 \%(n=31)$ were actively practicing their religion and $37.25 \%(n=19)$ were not. One participant chose not to answer these questions.

Next, we will continue with the summary and conclusion section. 


\section{Summary and Conclusions}

In nursing, it is vital that patients receive holistic care, or care of the mind, body and spirit. Leading nursing organizations and Joint Commission have put forth recommendations pertaining to the delivery of spiritual patient care. The topic of spirituality and spiritual care of patients has been included in nursing research for decades; however, current literature supports that nurses are feeling unprepared to provide this type of care. If spiritual assessment and care are an important element of holistic treatment of the patient, it is imperative that all nurses, including APRNs, feel confident and comfortable in providing this type of care (Chrash et al., 2011; Hubbell et al., 2006; Maddox, 2001; Weiland, 2010). Understanding the attitudes and knowledge of spirituality and spiritual care of APRN students may help graduate nursing education programs develop curriculum regarding the provision of spiritual care in nursing practice in the future.

Nurses may recognize spiritual needs and believe they are treating the patient holistically, but without consistent, formal training it is impossible to ascertain whether their patient's spiritual needs are actually being met. The findings of this study support what Lewinson and McSherry (2015) discovered regarding the nurses' role in the provision of spiritual care. It begs the question of whether spiritual assessments are actually being taught in nursing education programs. The literature pertaining to APRN education has also demonstrated that spiritual caregiving content is both required and necessary at the graduate level of nursing education, yet the inclusion of this important content has been neglected (Carron \& Cumbie, 2011; Hubbell et al., 2006; Maddox, 2001; Stranahan, 2001; Tanyi, et al., 2009; Weiland, 2010). 
A quantitative, one-time survey was conducted using a convenience sample of Masters of Nursing students at a small college in Rhode Island. The purpose of the survey was to assess attitudes and knowledge regarding spirituality and spiritual care of APRN students. Permission to conduct the survey was obtained from the IRB at the college. Demographic data collected included both male and female participants $(N=51)$, ranging in age from 21-59. The majority, $(96 \% ; n=49)$ worked either full or part time. Many participants, $(70.6 \% ; n=36)$ had worked in nursing from 1-10 years and most worked in critical care areas.

The survey demonstrated that the majority of participants believed spiritual care giving was the responsibility of a combination of people, including the patient and their family, clergy and the patient's own religious leader. Most participants had encountered a patient with a spiritual need at some time in their clinical practice. Participants stated they became aware of those needs primarily through conversation with and observation of their patients, as well as through family members. Many participants believed they were able to provide spiritual care for their patients although some did not. In regards to education and training in their undergraduate programs, the participants were relatively split on their views, with approximately half of them recalled receiving lecture content on spirituality and spiritual care. A few participants $(19.60 \% ; n=10)$ stated that they had received adequate education regarding spiritual care, while most $(78.43 \% ; n=40)$ did not. The majority $(86.26 \% ; n=44)$ of respondents considered spiritual care training to be the responsibility of a combination of institutions of higher education and employers/hospitals. Only a few $(11.76 \% ; n=6)$ participants had ever sought continuing education regarding spiritual care education and practices. The majority of the 
participants, $(80.39 \% ; n=41)$ reported having an affiliation with a religious group, while only $(60.78 \% ; n=31)$ conveyed they were active members within those groups.

Limitations were present in this study, one being the relatively small sample size. The research could have included more participants if performed during the course of the spring semester, when more students were enrolled in classes. Another possible limitation related to the specialties in which participants worked. The participants surveyed may not be afforded the time or opportunity to have in depth conversations with their patients about spiritual matters. Finally, the majority of the participants that answered questions pertaining to their own religious practice identified as Christian, specifically Catholic and this could have impacted the data as many religions/spiritual practices were not represented. Cultural considerations were not included in the survey instrument, although caring for patients of different cultures would impact the way spiritual care is provided.

In conclusion, the literature and findings in this study support the need for spiritual care curriculum content to be included in graduate nursing programs, and perhaps nursing programs overall. It may prove to be more valuable to introduce spiritual care content in undergraduate nursing programs at the outset, in both the classroom and clinical setting. This may ensure spiritual care of the patient is not being overlooked by nurses entering practice. Regardless, including such content in both programs of study can increase both RNs and APRNs confidence in providing holistic patient care, with the hope of improving patient outcomes. If content is implemented in in undergraduate and graduate nursing programs, more research would be necessary to judge its effectiveness in the future. 
Next, recommendations and implications for Advanced Nursing Practice will be considered. 


\section{Recommendations and Implications for Advanced Nursing Practice}

The findings in this study have implications for Advanced Practice Nurses in many areas, including their own practice, interdisciplinary practice, education, policy and research. Spiritual distress can have a detrimental effect on both the physical and mental health of patients. In relation to practice and education, it has been discussed that APRNs need to address their patients' spiritual concerns. If nurses are not taught how to provide spiritual care in a meaningful way, it is unlikely they will provide such care in practice, which could impact the quality of patient care. It is also important for a nurse to assess his or her own comfort level pertaining to discussing spiritual matters with patients. If an APRN is uncomfortable with the prospect of such discussions, spiritual care of the patient may be avoided altogether. One way to promote the adequate provision of spiritual care in practice is to integrate spiritual concepts, spiritual assessment tools, and spiritual care training into graduate nursing education. Additional methods include the use of reflective journaling, role play with students and participation in simulation scenarios geared toward spiritual care discussions.

In regard to interdisciplinary practice, APRNs are in a position to positively impact how their colleagues approach spiritual care of the patient by sharing and using evidence-based practice. In similar fashion, other disciplines bring their own expertise and ideas to the table and this type of interdisciplinary collaboration can improve the way spiritual care is approached and provided. The APRN has a unique opportunity to act as a change agent, positively influencing the way spiritual care is provided by an interdisciplinary team. 
Adding spiritual care content to current graduate curriculum could play a major role in improving patient outcomes. In this project, $78.43 \%(n=40)$ of participants did not feel their undergraduate training in spiritual care was sufficient. These results suggest that APRN graduate programs have to work to improve education in the spiritual dimension of patient care for nurses seeking to further their education. Integrating selfassessment modules may be beneficial for graduate nursing students, as modules such as these are usually self -directed, and can be completed outside of the classroom. As previously mentioned, journaling, group discussions, role-play and simulation are also suitable methods used to integrate the spiritual dimension of patient care.

The APRN also possesses the ability to influence policy change in regard to education at their own institutions and beyond by setting the standard for holistic spiritual care of patients. This could be accomplished by attending Quality Improvement meetings at their facility and providing team members with information regarding improvements in spiritual care practices. They can suggest and facilitate improvements in healthcare technologies such as the implementation of spiritual assessment tools into patients' electronic medical records and updating existing EMR's within their institutions. Facilitating understanding of different cultures and their religious practices is paramount as the diversity of the US population continues to grow. Maintaining cultural competencies within the spectrum of education and spiritual care is another area where APRNs can impact change and influence institutional policy and patient satisfaction. Perhaps most importantly, APRNs can pave the way for change within their local, state and national nursing organizations by vocalizing the importance and necessity 
of spiritual care for patients, through both publications and presentation of research at conferences.

Advanced practice nurses can be the face of change for a new generation in healthcare. Future research might include evaluating how educators feel about the subject of spiritual care education themselves, as well as where and how they may believe this type of education could be integrated into current curriculum. Other important research could include evaluating whether the addition of spiritual care education has a positive effect on improving the provision of spiritual care for patients and furthering positive patient outcomes.

Evidence from this project suggests that APRNs may not feel comfortable providing spiritual care to their patients'. Integrating spiritual assessment tools and other methods of spiritual care education into current graduate curricula could potentially improve APRNs ability to provide this vital and necessary care to their patients'. The addition of this curricula could also improve patient satisfaction and outcomes in the future and enhance APRNs relationships with their patients. 


\section{References}

AACN (2009). The Essentials of Baccalaureate Education for Professional Nursing Practice. American Association of Colleges of Nursing (AACN), Washington, DC.

Anandarajah, G., \& Hight, E. (2001). Spirituality and medical practice: Using the HOPE questions as a practical tool for spiritual assessment. American Family Physician, 63(1). 81-88.

Borneman, T., Ferrell, B., \& Puchalski, C. (2010). Evaluation of the FICA tool for spiritual assessment. Journal of Pain and Symptom Management, 40(2), 163-173.

Burkhart, L., \& Hogan, N. (2008). An experimental theory of spiritual care in nursing practice. Qualitative Health Research, 18, 928-938.

Burkhart, L., Schmidt, L., \& Hogan, N., (2011). Development and psychometric testing of the spiritual care inventory instrument. Journal of Advanced Nursing, 67 (11), 2463-2472. doi:0.1111/j.1365-2648.2011. 05654.x

Burnard, P., (1988). The spiritual needs of atheists and agnostics. Professional Nurse, 4 (3), 130-132.

Calabria, M. D., \& Macrae, J. A. (Eds.). (1994). Suggestions for thought by Florence Nightingale: Selections and Commentaries. Philadelphia: University of Pennsylvania Press.

Carr, T. (2013). Mapping the processes and qualities of spiritual nursing care. Qualitative Health Research, 18, 686-700. doi:10.1177/1049732307308979 
Carron, R., \& Cumbie, S. A., (2011). Development of a conceptual nursing model for the implementation of spiritual care in adult primary healthcare settings by nurse practitioners. Journal of the American Academy of Nurse Practitioners, 23, 552560. doi: 10.1111/j.1745-7599.2011.00633.x

Cavendish, R., Luise, B. K., Russo, D., Mitzeliotis, C., Bauer, M., Bajo, M.A.M., Calvino, C., Horne, K. \& Medefindt, J. (2004). Spiritual perspectives of nurses in the United States relevant for education and practice. Western Journal of Nursing Research, 26, 196-212.

Cawley, N. 1997. An exploration of the concept of spirituality. International Journal of Palliative Nursing 3(1), 31-36.

Chrash, M., Mulich, B., Patton, C.M. (2011). The APN role in holistic assessment and integration of spiritual assessment for advanced care planning. Journal of the American Academy of Nurse Practitioners, 23, 530-536.

Galloway, S. (2016). Spiritual Immersion: Developing and Evaluating a Simulation Exercise to Teach Spiritual Care to Undergraduate Nursing Students. (Unpublished doctoral dissertation). College of Nursing and Health Professions, University of Indiana.

Giske, T. (2012). How undergraduate nursing students learn to care for patients spiritually in clinical studies-a review of the literature. Journal of Nursing Management, 1-9. doi:10.1111/jonm. 12019.

Goldberg, B. (1988). Connection: A explanation of spirituality in nursing care. Journal of Advanced Nursing, 27, 836-842.

Heriot, C. S. (1992). Spirituality and ageing. Holistic Nursing Practice, 7, 22-31. 
Hubbell, S. L., Woodard, E. K., Barksdale-Brown, D. J., \& Parker, J. S., (2006). Spiritual care practices of nurse practitioners in federally designated nonmetropolitan areas of North Carolina. Journal of the American Academy of Nurse Practitoners, 18, 379-385.

Joint Commission on Accreditation of Healthcare Organizations. (2009). Retrieved from http//www.jointcommission.org/AccreditationPrograms/HomeCare/Standards/09_ FAQs/PC/Spiritual_Assessment

Labun, E., (1988). Spiritual care: An element in nursing care planning, Journal of Advanced Nursing, 13, 314-320.

Lewinson, L. P., McSherry, W., \& Kevern, P. (2015). Spirituality in pre-registration nursing practice: A review of the literature. Nurse Education Today, 35, 806-814.

Maddox, M. (2001). Teaching spirituality to nurse practitioner students: The importance of interconnection of mind, body, and spirit. Journal of the American Academy of Nurse Practitioners, 13 (3), 134-139.

McSherry, W. (2006). Making sense of spirituality in nursing and health care practice: An interactive approach (2nd ed.). Philadelphia, PA: Jessica Kingsley Publishers.

McSherry, W. \& Ross, L. (2002). Dilemmas of spiritual assessment: Consideration for nursing practice. Journal of Advanced Nursing, 38, 439-488.

McSherry, W., Cash, K., \& Ross, L., (2004). Meaning of spirituality: Implications for nursing practice. Journal of Clinical Nursing, 13, 934-941. 
McSherry, W., Draper, P., \& Kendrick, D. (2002). The construct validity of a rating scale designed to assess spirituality and spiritual care. International Journal of Nursing Studies, 39, 723-734.

McSherry, W., \& Jamieson, S. (2011). An online survey of nurses' perceptions of spirituality and spiritual care. Journal of Clinical Nursing, 20 (11/12), 1757-1767. doi:10.1111/j.1365-2702.2010.03547.x

Narayanasamy, A. (1999). ASSET: A model for auctioning spirituality and spiritual care education and training in nursing. Nurse Education Today, 19, 274-285.

Narayanasamy, A., \& Owens, J. (2001). A critical incident study of nurses' responses to the spiritual needs of their clients. Journal of Advanced Nursing, 33, 446-455.

Nardi, D., \& Rooda, L. (2011). Spirituality-based practice by nursing students: An exploratory study. Journal of Professional Nursing, 27(4), 255-263.

Nightingale, F. (1969). Notes on nursing: What it is and what it is not. New York, NY: Dover Publications, Inc.

National Organization of Nurse Practitoner Faculties (NONPF), (2012), Nurse Practitoner Core Competencies. Retieved from: http://c.ymcdn.com/sites/www.nonpf.org/resource/resmgr/competencies/npcoreco mpetenciesfinal2012.pdf

North American Nursing Diagnosis Association (NANDA), (2007). Nursing diagnoses: Definition \& classification, 2007-2008.

O’Brien, M. E. (2003). Spirituality in nursing: Standing on holy ground. (2nd ed.). Boston: Jones and Bartlett. 
Polit, D. F., \& Beck, C.T. (2012). Nursing research generating and assessing evidence for nursing practice. ( $9^{\text {th }}$ ed.). Philadelphia: Wolters Kluwer Health/Lippincott Williams \& Wilkins.

Puchalski, C. (1999). A spiritual history. Supportive Voice, 5, 12-13.

Rooda, L., (1992). The development of a conceptual model for multicultural nursing. Journal of Holistic Nursing, 10, 337-347.

Sessanna, L., Finnell, D. S., Underhill, M., Chang, Y. P., \& Peng, H. L. (2011). Measures assessing spirituality as more than religiosity: A methodological review of nursing and health-related literature. Journal of Advanced Nursing, 67, 1677-1694. doi:10.1111/j.1365-2648.2010.05596.x

Stranahan, S. (2001). Spiritual perception, attitudes about spiritual care, and spiritual care practices of nurse practitioners. Western Journal of Nursing Research, 23(11), 90104.

Tanyi, R. A. (2002). Toward clarification of the meaning of spirituality. Journal of Advanced Nursing, 39, 500-509.

Taylor, E. J., \& Mamier, I. (2013). Nurse responses to patient expressions of spiritual distress. Holistic Nursing Practice, 27(4), 217-224. doi:10.1097/HNP.0b013e318294e50a

Taylor, E. J., Park, C. G. \& Pfeiffer, J. B. (2014). Nurse religiosity and spiritual care. Journal of Advanced Nursing, 70(11), 2612-2621. doi: 10.1111/jan.12446 
Timmins, F., Neill, F., Murphy, M., Begley, T., \& Sheaf, G., (2015). Spiritual care competence for contemporary nursing practice: A quantitative exploration of the guidance provided by fundamental nursing textbooks. Nurse Education in Practice., xxx, 1-7. http://dx.doi.org/10.1016/j.nepr.2015.02.007

Watson, J., (2001). Theory of human caring. In Nursing Theories and Nursing Practice (Parker, M. E., ed.), F. A. Davis Co. Philadelphia, pp. 343-360.

Watson, J. (2002). Intentionality and caring-healing consciousness: a practice of transpersonal nursing. Holistic Nursing Practice 16, 12-19.

Weiland, S. (2010). Intergrating spirituality into critical care: An APN perspective using Roys adaptation model. Critical Care Nursing Quarterly, 33(3), 282-291. doi: 10.1097/CNQ.0b013e3181ecd56d. 
Appendix A

RESEARCH ADDRESSING NURSES' PERCEPTIONS OF SPIRITUAL CARE

PLEASE CAN YOU GIVE THE NECESSARY INFORMATION ABOUT

YOURSELF. IT IS VERY IMPORTANT THAT YOU COMPLETE THE

QUESTIONNAIRE BY YOURSELF AND THAT YOU ANSWER ALL THE

APPROPRIATE QUESTIONS

Although the Questionnaire looks quite lengthy it shouldn't take you long to complete (There are no right or wrong answers so please answer honestly)

\section{$\underline{\operatorname{Part} \mathrm{A}}$}

(Please place a check in the appropriate box.)

1) Are you? Male

Female

2) To which age group do you belong? (Please circle)

$$
\begin{array}{lll}
21-29 & 30-39 & 40-49 \\
50-59 & 60 \text { or above }
\end{array}
$$

$\underline{\text { Part B }}$

1) What is your present qualification/rank?

Charge Nurse __ Senior Nurse __ Staff Nurse __ EN__ Auxiliary__ Nurse Care Assistant

Other (please specify)

2) Do you work:

Full Time

Part Time 


\section{3) Do you work:}

Internal Rotation (Days \& Nights)

Permanent Nights

Permanent Days

Other (please specify)

4) How long have you been working as a Qualified Nurse/Care assistant?

Less than 1 year $1-5$ years 6 - 10 years $11-25$ years

25 years and above

5) What type of nursing specialty are you presently working in?

\section{$\underline{\text { Part C }}$}

SPIRITUALITY AND SPIRITUAL CARE RATING SCALE

FOR EACH QUESTION PLEASE CIRCLE ONE ANSWER WHICH BEST

REFLECTS THE EXTENT TO WHICH YOU AGREE OR DISAGREE WITH EACH STATEMENT.

a) I believe nurses can provide spiritual care by arranging a visit by the hospital Chaplain or the patient's own religious leader if requested

$\begin{array}{llll}\text { Strongly Disagree } & \text { Disagree } & \text { Uncertain } & \text { Agree }\end{array}$ Agree

b) I believe nurses can provide spiritual care by showing kindness, concern and cheerfulness when giving care Strongly Disagree Disagree Uncertain Agree Strongly Agree c) I believe spirituality is concerned with a need to forgive and a need to be forgiven Strongly Disagree Disagree Uncertain Agree Strongly Agree 
d) I believe spirituality involves only going to Church/Place of Worship

Strongly Disagree Disagree Uncertain Agree Strongly Agree

e) I believe spirituality is not concerned with a belief and faith in a God or Supreme Being

Strongly Disagree Disagree Uncertain Agree Strongly Agree

f) I believe spirituality is about finding meaning in the good and bad events of life Strongly Disagree Disagree Uncertain Agree Strongly Agree

g) I believe nurses can provide spiritual care by spending time with a patient giving support and reassurance especially in time of need

Strongly Disagree Disagree Uncertain Agree Strongly Agree

h) I believe nurses can provide spiritual care by enabling a patient to find meaning and purpose in their illness

Strongly Disagree Disagree Uncertain Agree Strongly Agree

i) I believe spirituality is about having a sense of hope in life

Strongly Disagree Disagree Uncertain Agree Strongly Agree

j) I believe spirituality is to do with the way one conducts one's life here and now Strongly Disagree Disagree Uncertain Agree Strongly Agree

k) I believe nurses can provide spiritual care by listening to and allowing patients' time to discuss and explore their fears, anxieties and troubles

Strongly Disagree Disagree Uncertain Agree Strongly Agree

1) I believe spirituality is a unifying force which enables one to be at peace with oneself and the world

Strongly Disagree Disagree Uncertain Agree Strongly Agree 
m) I believe spirituality does not include areas such as art, creativity and selfexpression

Strongly Disagree Disagree Uncertain Agree Strongly Agree

n) I believe nurses can provide spiritual care by having respect for privacy, dignity and religious and cultural beliefs of a patient

Strongly Disagree Disagree Uncertain Agree Strongly Agree

o) I believe spirituality involves personal friendships, relationships

Strongly Disagree Disagree Uncertain Agree Strongly Agree

p) I believe spirituality does not apply to Atheists or Agnostics

Strongly Disagree Disagree Uncertain Agree Strongly Agree

q) I believe spirituality includes people's morals

Strongly Disagree Disagree Uncertain Agree Strongly Agree

1) Who do you feel should be responsible for providing Spiritual Care?

(Please check box (es) which apply)

Nurses _ C Chaplains/Clergy__ Combination Nurses/Chaplains_ Patients

Themselves_

Combination of Nurses/Chaplain and patients themselves_

Patient, Family and Friends __ Patients Own Spiritual/ Religious Leader

__Combination of all: (Nurses/Chaplain, Patient/Patient's Family/Friends/Own

Religious Leader)

Other (please specify) 
2) In your clinical practice have you ever encountered a patient(s) with a spiritual need(s)?

Yes___ No____ (If no please move onto question 4)

If yes, how did you become aware of this need(s)? (Please pick the box (es) which apply) Patient himself/herself___Patient's relatives/friends___Nursing care plan___Other Nurses

Chaplains/religious leaders___Listening to and observing the patient

Other

(If other please give details)

IF YOU ARE A QUALIFIED NURSE PLEASE ANSWER THE FOLLOWING

QUESTIONS. IF YOU ARE AN UNQUALIFIED NURSE MOVE ON TO QUESTION SEVEN.

3) Do you feel that you are usually able to meet your patients Spiritual Needs? Yes___ No_ (If No, please give details)

4) During the course of your nurse training did you receive any lessons/lectures covering Spiritual Care?

Yes No 
(If Yes, please give details)

4a) Where did you undertake your Nurse training, please give details

5) Since qualifying as a nurse have you been on any training courses which covered Spiritual Care?

Yes _ No

(If yes, please give details of training course - stating whether you feel this has enabled you to better meet your patient's spiritual needs)

6) Do you feel nurses receive sufficient training on matters concerning Spiritual Care?

Yes _ N No

7) If Nurses are to receive instruction concerning Spiritual Care which of the following do you feel should be responsible for this?

Colleges of Health __ Training Department ___ Nurses themselves A combination of all the above

Other (please specify) 


\section{$\underline{\text { Part D }}$}

As it is possible that connections may exist between religious affiliation and certain responses given, I would appreciate if you would answer the following two questions.

1) Do you have a religion?

Yes _ No N

(If Yes, please state)

2) Are you practicing your religion?

Yes _ No N

If Yes - please briefly describe in what capacity you practice i.e. attend Services Weekly, Yearly

etc.

\section{$\underline{\text { Part E }}$}

PLEASE ONLY COMPLETE THIS SECTION IF YOU HAVE CHOSEN NOT TO COMPLETE THE QUESTIONNAIRE.

If you have chosen not to complete the questionnaire, would you mind sharing your reasons with me? 
I decided not to complete the questionnaire because

May I thank you for taking the time to complete this questionnaire. Can you place the completed questionnaire in the addressed envelope provided and return as soon as possible. 